\title{
MATERIALIZACIÓN DE LA NORMA. CITAS Y REITERACIONES EN LA COLECCIÓN JUAN BAUTISTA SIMONI
}

\author{
Materialization of the norm. Quotes and iterations in Juan Bautista Simoni \\ collection
}

\section{Guadalupe Arqueros*}

\section{Resumen}

Este artículo retoma el concepto de norma desarrollado por Judith Butler y analiza la producción de sujetos generizados en fotografías, visualizando citas y parodias, lugares de eficacia, fallas y fracturas. Utilizando la noción de norma como forma de producción del estándar común, regulador de los fenómenos sociales y como medida de comparación y referencia del grupo consigo mismo. Teniendo en cuenta que no es externa al campo de su aplicación y no solo es responsable de originarlo, sino que confiere realidad. Su poder se origina en la cita y la reiteración. El análisis de la colección fotográfica Juan Bautista Simoni (Ca. 1900) nos permitirá ver cómo el campo de eficacia de las normas es el telón de fondo sobre el cual se recorta el género en sus dimensiones idealizadas y las maneras en que el dispositivo fotográfico funciona integrando un régimen sexual regulador. En este marco se explora el modo en que las imágenes han funcionado como construcciones discursivas de cuyo seno nacen sujetos que reiteran la regulación de lo masculino y lo femenino, como verdades naturales ahistóricas. Además, nos interesa reflexionar sobre cómo las fotografías cimentan identidades genéricas débilmente formadas humanizando y enmarcando los cuerpos en un régimen biopolítico que, aunque con pliegues y fracturas, resulta igualmente eficaz. El presente trabajo se encuadra en la tradición de los estudios de géneros, entendidos como prácticas de crítica cultural; en tanto interpela los procesos de producción ideológica de signos en la presentación y representación de las imágenes.

$$
<\text { Fotografía }><\text { Género }><\text { Simoni }><\text { Norma }>
$$

\begin{abstract}
This article is based on the concept of norm developed by Judith Butler and the production of gendered subjects in photograhs is analyzed. Quotes, parodies, effectiveness places, failures and fractures are visualized. The notion of norm is conceived as a way of producing a common standard, regulator of social phenomena and as measure of comparison and reference of the group with itself. Bearing in mind that the norm is not external to its field of application and it is not only responsible of originating it, but also lends reality. Its power is originated in the quote and the iteration. The analysis of Juan Bautista Simoni's photographic collection (c1900) will allow us to see how the field of effectiveness of norms is the background on which gender is silhouetted in its idealized dimensions, and the ways in the photographic device contributes to a sexual regulator regimen. In this framework, the manner in which images have functioned as discursive constructions from which subjects that iterate the regulation of the masculine and the feminine as a natural ahistorical truth are born will be explored. Besides, we reflect on how photographs reinforce gendered identities weakly shaped, humanizing and framing the bodies on a biopolitical regime. This regime has folds and fractures, but it turns out to be effective. This work is framed on the tradition of gender studies, understood as cultural criticism practices; it interpellates the processes of ideological production of signs in the presentation and representation of pictures.
\end{abstract}

$<$ Photograph $><$ Gender $><$ Simoni $><$ Norm $>$

Recibido: 20/07/2018 //Aceptado: 15/10/2018

* Universidad Nacional del Nordeste (UNNE), Argentina. Instituto de Investigaciones Geohistóricas (IIGHI), Consejo Nacional de Investigaciones Científicas y Técnicas, gimenarqueros@gmail.com 
Arqueros. Materialización de la norma. Citas y reiteraciones en la colección Juan Bautista Simoni.

\section{Encuadre}

El movimiento político igualitarista que reivindica el lugar de las mujeres en el espacio público y de toma de decisiones, la división sexual del trabajo, la relevancia de sus experiencias y hasta la protección de su vida contra muertes y abusos (junto a otras reivindicaciones) se llama feminismo. En tanto "estudios de género" se ha reservado para la traducción epistémica de esta perspectiva; señalando no sólo con mayor relevancia el lugar de las mujeres en la construcción de la historia de la cultura sino también marcando la clara desigualdad política y representativa, no numérica ni cuantitativa en la mayoría de las sociedades y sus instituciones. Estas dos vertientes de un mismo fenómeno (feminismo y estudios de género) conllevan una actitud crítica del ámbito microestructural donde se despliegan a diario infinitas interacciones humanas; al mismo tiempo que proponen la transformación y eliminación del sesgo androcéntrico en las ciencias (Puleo, 2000).

Nos interesa reflexionar en el presente trabajo a la luz de las llamadas hermenéuticas de la sospecha, en la que podríamos encuadrar la tradición del pensamiento feminista. Dentro de los estudios de género encontramos múltiples perspectivas de abordaje centradas en cuatro planos: fáctico, teórico, de las prácticas y meta teórico (Santa Cruz y otras, 1994). Las teorías legitiman las prácticas y fundamentan la experiencia. La metateoría analiza a cada una de ellas con sus interacciones correspondientes y las que articulan los planos anteriores son las consideradas metateóricas. En este sentido la filosofía y las ciencias humanas han tenido una clara relación con la fundamentación del poder y las áreas asignadas a varones y mujeres, junto a la correspondiente distribución de tareas y actividades (Puleo, 2000). Para desmontar los sesgos negativos se introduce un tipo de perspectiva metodológica y de análisis denominada de género, utilizada desde la década del 60 en los Women Studies, estudios feministas o estudios de género ${ }^{1}$.

Aquí retomamos la tradición de los estudios de género que los afirma como crítica cultural desde una doble perspectiva:

1) es crítica de la cultura, en tanto examina los regímenes de producción y representación de los signos que escenifican las complicidades de poder entre discurso, ideología, representación e interpretación en todo aquello que circula y se intercambia como palabra, gesto e imagen, y 2) es una crítica de la sociedad realizada desde la cultura, que reflexiona sobre lo social incorporando la simbolicidad del trabajo expresivo de las retóricas y las narrativas a su análisis de las luchas de identidad y de las fuerzas de cambio. (Richard, 2009: 79)²

El análisis visual desde la perspectiva de género tiene una trayectoria que se inicia en la década del 70, momento en que las teorías se concentraron en denunciar

\footnotetext{
1 Para una ampliación de la perspectiva metodológica y su relevancia en las ciencias sociales, véase Harding S. 1987, Is There a Feminist Method? Feminism and Methodology.

2 Cursiva del original.
} 
las imágenes estereotipadas de las mujeres y la inscripción masculina y activa del rol del espectador. La retórica de las imágenes y la construcción de sus sentidos se entendía vinculada a una realidad que era social y que estaba por fuera de ellas pero que lograba su expresión allí. El patriarcado, la ideología y el sexismo convertían a las mujeres en objetos que se miraban a sí mismas a través de los ojos del deseo masculino y sus cuerpos se pasivizaban para el placer escópico del propietario de la obra o de la fotografía (Berger, 1975). Desde esta posición teórica el concepto de representación (sostenido en un realismo ingenuo que luego se va complejizar) postulaba un escenario desigual expresado en las imágenes. Algunas autoras que sostuvieron esta posición fueron Griselda Pollock que analizó publicidades, fotografías, pornografía y pinturas del siglo XIX, Hilary Robinson una historiadora del arte y Laura Mulvey, interesada en el relato cinematográfico, entre otras (Torricela, 2011).

Con el advenimiento del psicoanálisis lacaniano, el pos-estructuralismo y la deconstrucción; la visión lineal del realismo, que solventaba la posición anterior se quiebra y comienza a ganar espacio una complejización en las ciencias sociales y con ellas por supuesto en los estudios visuales. Desde estas nuevas concepciones los sujetos son producidos en los lenguajes y mediante las tecnologías de los discursos. Un ejemplo de esta posición es la tesis con la que concluye Michel Foucault el último capítulo de "Las palabras y las cosas" (cuya primera edición es de 1966). Para el autor las ciencias humanas fueron quienes dieron origen al sujeto moderno y el hombre como lo entiende la antropología es una invención relativamente reciente (Foucault, 1998). ${ }^{3}$

Deudora de esta escuela francesa será la visión más contemporánea que considera que se deviene sujetos a través de una reglamentación. Es decir que los discursos reguladores que forman al sujeto del género son quienes delimitan la subjetividad toda (Butler, 2010). Esto propició un giro en el análisis de los estudios visuales que comenzaron a considerar las imágenes (en especial la publicidad de los medios masivos) como mecanismos que constituían sujetos y los producían. En el marco de esta segunda vertiente conceptual se encuadra nuestro trabajo y lo que Judith Butler va denominar generización. $^{4}$

\section{Generización}

Para el feminismo tradicional el género es una construcción cultural que las sociedades elaboran sobre el sexo biológico y que determina, con variaciones el rol que se le asigna a bio varones y mujeres, las diferencias jerárquicas, la distribución de tareas

\footnotetext{
3 En todo caso una cosa es cierta que el hombre no es el problema más antiguo ni el más constante que se haya planteado el saber humano. Al tomar una cronología relativamente breve y en un corte geográfico restringido, la cultura europea a partir del siglo XVI, puede estarse seguro de que el hombre es una invención reciente. (1998:375).

4 Butler (2008) precisa una definición de este concepto ...no está muy claro que pueda haber un "yo" o un "nosotros" que no haya sido sometido, que no esté sujeto al género, si por "generización" se entiende, entre otras cosas, las relaciones diferenciadoras mediante las cuales los sujetos hablantes cobran vida. Sujeto al género, pero subjetivado por el género, el "yo" no está ni antes ni después del proceso de esta generización, sino que solo emerge dentro (y como la matriz de) las relaciones de género mismas (2008:25).
} 
y el status global (Puleo, 2000; Badinter, 1993). Posee distintos componentes como la identidad sexuada, las normas, los estereotipos y las sanciones. Las teorías queer contemporáneas sin embargo ponen en perspectiva la masculinidad y femineidad binaria considerándolas actos performativos que muestran que no existe original y copia y que todo género es un disfraz, una impostura y una cita perpetua sin referencia destinada a reproducir jerarquías(Butler, 2008). El género, para este pensamiento contemporáneo, es el aparato a través del cual tiene lugar la producción y normativización de lo femenino y lo masculino junto con las formas hormonales, cromosómicas, psíquicas y performativas que asume. Pero a su vez podría convertirse en el aparato que una vez desmantelado, deconstruya y desnaturalice los términos. Presentado así, el dispositivo funciona tanto para instaurar la norma como para socavar esa misma instauración, revelando su incompletud (2010).

En estos términos Butler difiere de Foucault cuando éste considera que el cuerpo es la superficie grabada por la historia, como el escenario de la inscripción cultural. El género (y su gestión) vendrían a constituir inscripciones sobre el sexo biológico. Pese a que para el autor francés ni siquiera el cuerpo es lo suficientemente estable, su obra sugiere una materialidad anterior a la significación y a la forma (Foucault, 2008). Sin embargo, Butler retoma la tradición genealógica y se aparta concentrándose en describir la norma que habría permitido la imitación de géneros. En ese proceso descubre y elabora su hipótesis de que no puede existir una lectura primaria del sexo en su materialidad pura, así como no existe un sujeto por fuera de los discursos. La lectura de la materialidad biológica es ya una inscripción sin prioridad con el género asignado:

....actos, gestos y deseo crean el efecto de un núcleo interno o sustancia, pero lo hacen en la superficie del cuerpo, mediante el juego de ausencias significantes que evocan pero nunca revelan, el principio organizador de la identidad como causa. Dichos actos, gestos, e interpretaciones son performativos en el sentido de que la esencia o la identidad que pretenden afirmar son invenciones fabricadas y preservadas mediante signos corpóreos y otros medios discursivos. El hecho de que el cuerpo con género sea performativo muestra que no tiene una posición ontológica distinta de los diversos actos que conforman su realidad. (Butler, 2007: 266) ${ }^{5}$

La clasificación tradicional de sexo y género tiene su clivaje en la metafísica de la presencia, que postula la existencia de sujetos por fuera de las configuraciones o construcciones culturales; como sustratos previos y con un núcleo identitario no configurado que la cultura vendría a sobreimprimir. Sin embargo, no hay diferencias materiales que de algún modo escapen a la inteligibilidad de las prácticas discursivas. La teoría performativa considera que los géneros son parodias o actuaciones, no de un original que se busca imitar sino de la noción misma de original (Butler 2007:269). La

\footnotetext{
Cursiva del original.
} 
identidad de género puede definirse como la historia personal/cultural de significados asumidos y de prácticas imitativas que crean la ilusión de un yo primario o interno y parodian el mecanismo mismo de esa construcción. En este marco teórico los atributos del género no son expresivos sino performativos y no revelan una identidad preexistente, sino una imitación sin un origen. La performatividad es entendida como una práctica reiterativa que produce los efectos que nombra y son los sujetos quienes emergen en estas relaciones.

Volviendo al trabajo, nuestra intención es retomar el concepto butleriano de norma y analizar la producción de los cuerpos de mujeres y varones en las fotografías para visualizar citas y parodias, junto a sus lugares de eficacia, sus fallas y fracturas. Teniendo en cuenta que la performatividad no es un acto singular sino una reiteración que fija una norma o un conjunto de ellas y disimula las convenciones de las que es una repetición. El análisis nos ayudará a ejemplificar cómo el campo de realidad que crean las normas es el telón de fondo sobre el cual se recorta el género en sus dimensiones idealizadas. Si bien se hace imposible reconstruir una narrativa completa de la historia citacional de la norma (2010: 83) nos interesa indagar en la posibilidad de ver a las colonias como laboratorios culturales de experimentación y plantearlos como los bordes o márgenes de las practicas centrales, tanto europeas como locales. Usaremos el concepto de norma como forma de producir el estándar común y reguladora de los fenómenos sociales, como medida de comparación y referencia del grupo consigo mismo. La norma no es externa al campo de su aplicación y no sólo es responsable de originarlo, sino que se produce a sí misma en la fundación del campo, a la vez que confiere realidad. Su poder se halla en la cita y la reiteración. ${ }^{6}$

\section{Inmigrantes y funciones de la fotografía}

Trabajaremos con la colección fotográfica Juan Bautista Simoni realizada entre 1890 y 1930 y compuesta de 90 negativos en placas de vidrio, de los que se extrajeron 72 copias en papel. ${ }^{7}$ Una primera clasificación de las escenas divide las temáticas en retratos individuales y grupales, escenas familiares, acontecimientos sociales, sucesos rurales y vías de comunicación. Se sospecha que los padres de Simoni trajeron de Europa

\footnotetext{
${ }^{6}$ Butler profundiza el concepto para aplicarlo específicamente a las normas de género retomando la tradición foucaultiana (de La Historia de la Sexualidad y Los anormales) y vinculándolo con el perfil jurídico de Francois Ewald. Para un desarrollo pormenorizado véase Deshacer el género, capítulo 2: El reglamento del género (Butler, 2010).

${ }^{7}$ La colección está integrada por 90 negativos (placas secas de vidrio de $2 \mathrm{~mm}$. de espesor) cuyas medidas son 13 x $18 \mathrm{~cm}$. La emulsión es gelatina-bromuro con sales de plata como formadoras de la imagen. Fue entregada en comodato por una familia heredera de Simoni para su conservación, copiado, digitalización e investigación (Giordano y Sudar Klappenbach, 2012) Integra el fondo documental del Núcleo de Estudios y Documentación de la Imagen (NEDIM) perteneciente al Instituto de Investigaciones Geohistóricas (IIGHI) Unidad Ejecutora del Consejo Nacional de Investigaciones Científicas y Técnicas (CONICET) de doble pertenencia con la Universidad Nacional del Nordeste (UNNE). Todo cito en la ciudad de Resistencia, Provincia del Chaco, República Argentina. Un grupo de trabajo del NEDIM llevó a cabo las tareas de rescate, conservación y guarda. El proceso fue financiado por el proyecto Estudios y Proyectos Provinciales del CFI y publicado en el año 2012 (Giordano y Sudar Klappenbach).
} 
Arqueros. Materialización de la norma. Citas y reiteraciones en la colección Juan Bautista Simoni.

vagos conocimientos sobre el uso de la cámara y que estas ideas fueron transmitidas a su hijo, quien siendo mayor visitaba a los inmigrantes los días feriados y domingos para tomarle una foto familiar (Reyero y Sudar Klappenbach, 2012). Debido a la escasa bibliografía no se cuenta con datos técnicos de la cámara utilizada ni las fechas precisas de las tomas. Tampoco hay información sobre los nombres propios de las mujeres y hombres protagonistas de las fotografías (2012:24).

Con respecto a la composición de las colonias, el primer grupo de inmigrantes que llegó al Chaco estaba integrado por 43 familias friulanas (250 personas) que provenían de la región de Udine y arribaron al puerto San Fernando el 27 de enero de 1978 (Beck, 2001; Reyero y Sudar Klappenbach, 2010). Esta ocupación se encontraba precedida por pobladoras y pobladores originarios además de obrajeros de la provincia vecina de Corrientes que trabajaban desde mediados de 1800 en la explotación forestal. No obstante el poblamiento "oficial" del Chaco por el hombre "blanco" fue precedido por numerosas campañas militares de avance de frontera y el exterminio de los pueblos originarios que ocupaban estos suelos (Reyero y Sudar Klappenbach, 2010: 80).

Al momento de analizar un corpus similar, donde están incluidos algunos ejemplares de la Colección Simoni, las autoras identifican tópicos principales y reiterativos. ${ }^{8}$ Bodas, comuniones y velatorios, son las ocasiones extraordinarias de celebración y conmemoración donde el acto fotográfico cumple dos funciones primordiales:

A través de las imágenes los inmigrantes relatan aspectos de sus historias de vida y al hacerlo construyen una imagen de sí mismos, un modo de ser inmigrantes en tierras chaqueñas frente a la alteridad que los acompañaba (pueblos originarios y criollos) (2012:98).

Las fotografías funcionan como señaladores en las actividades comunales trascendentes, debido a ello abundan las escenas de casamientos, bautismos, visitas ilustres y decesos. Estas imágenes eran utilizadas para emparentar los grupos familiares y humanos entre sí hacia el interior y reforzar el vínculo con los residentes en las tierras europeas a quienes se informaba del mantenimiento de las costumbres y procederes, hacia el exterior.

Otro antecedente destacado que retomamos, es el libro de Hugo Beck (2001) sobre la conformación de la población inmigrante en el Chaco a partir de 1978 y su adaptación al territorio junto con la población interna, criolla y originaria. El libro historiza los intercambios de quienes integraban las colectividades y como esto conllevó según el autor a un enriquecimiento espiritual (Beck, 2001: 140). Nos interesa además

\footnotetext{
${ }^{8}$ El corpus analizado en Memorias de la inmigración. Historias de vida de los inmigrantes europeos en el Chaco a través de sus fotografías (Reyero y Sudar Klappenbach, 2010) se compuso de alrededor de cincuenta fotografías entregadas en comodato al NEDIM y donadas al Museo Histórico Ichoalay de Resistencia (2010:78). Entre ellas había imágenes tomadas por Juan Bautista Simoni. De allí la importancia de este antecedente para nuestro trabajo.
} 
el análisis del contexto regional que realiza y las incipientes faenas de quienes poblaban las aéreas rurales.

Beck describe, mediante un extenso trabajo en los archivos censales y del registro civil, los orígenes registrados de los asentamientos coloniales, la exploración del territorio, su trazado y mensura para el posterior loteo, desde la promulgación de la Ley Nacional $N^{\circ} 817$ en el año 1876. Dicha ley organizaba dos tipos diferentes de colonización, la directa por parte del Estado (fue el caso de Resistencia) y la privada en Margarita Belén, Benítez, Popular y Amalia. El señalamiento que hace el autor, sobre el alto índice de varones que llegó por vía marítima al país favoreció la heterogamia y su consideración trajo como consecuencia que la mujer argentina sea la que estableció un puente entre nativos y extranjeros (Beck, 2001:138).

A pesar de que entre los miembros de las diversas nacionalidades, en especial los de mayor edad, hay inquietudes por conservar la tradición, ha ido perdiendo fuerza la presión del grupo sobre el individuo y ha ido ganando espacio la idea de que debe concederse a cada persona la libertad de escoger de la cultura de su grupo étnico lo que ella quiera y de tomar de otras culturas lo que considere mejor. (Beck, 2001:140).

Se observa una variación en la composición de la población inmigrante entre los años 1895 y 1914, seleccionados por el autor. La tendencia es a aumentar la presencia de inmigrantes del Paraguay y España, que reemplazan a quienes provenían de Italia en el segundo puesto cerca de 1914 y a quienes llegaban de Austria, que en las oleadas iniciales (1895) figuraban en el cuarto puesto de la pirámide poblacional de las colonias (:32-33). De entre esa composición de orígenes diversos un rasgo que previsiblemente se mantiene en ambos períodos es el llamado índice de masculinidad o razón entre sexos. Recordamos que el índice, razón o tasa de masculinidad es la expresión más usual utilizada en el análisis poblacional por sexos. Implica el conocimiento del número de habitantes de cada sexo e indica el número de varones por cada cien o cien mil mujeres; de esta variable se desprenden otras dimensiones como ser masculinidad por edad, según condición urbana rural, según lugar de nacimiento y/o país de nacimiento, condición de alfabetización, etc. (Bolsi, Osuna, Meichtry; 1981: 45).

Sobre estos antecedentes trabajaremos una descripción de las escenas y los grupos humanos que las componen. El análisis considerará a los documentos fotográficos como un tipo específico de producto en una realidad social y atravesado por ella; retomando la tesis de Geoffrey Batchen que afirma que no existe una fotografía primitiva en mayor medida que un lenguaje primitivo (2004: 179) y que es erróneo considerar a los primeros fotógrafos como ingenuos y vacilantes en la composición de sus escenas. Entendemos las imágenes como lugares de una compleja intertextualidad, produciendo y difundiendo significados latentes en una coyuntura social e histórica determinada (2004:17) y en la certeza de que las fotografías nunca son prueba de la historia; sino que ellas mismas son lo histórico (Tagg, 2005: 87). 
Arqueros. Materialización de la norma. Citas y reiteraciones en la colección Juan Bautista Simoni.

El procedimiento se inicia con la técnica de la descripción de datos visuales (Flick, 2004) y luego el movimiento inferencial de los aspectos explícitos y latentes performados por quienes protagonizan las escenas. Considerando que el género es una norma tenuemente incorporada (Butler, 2010) en cualquier actor social y que rige la inteligibilidad social misma. ${ }^{9}$ El objetivo es centrarse en la manera en que las imágenes construyen la norma, e indagar en la posibilidad de pensar la fotografía como un régimen sexual regulador en tanto daría lugar a que ciertos tipos de marcaciones de género (posiciones, prácticas y acciones de quienes protagonizan las fotos) sean reconocibles como imponiendo legibilidad y produciendo parámetros de personas. ${ }^{10}$

Siguiendo la sistematización del inventario la colección se compone de 50 retratos, 18 acontecimientos sociales, 17 fotos rurales, 4 reuniones familiares y 1 imagen de vías de comunicación. ${ }^{11}$ Para este trabajo realizamos una primera clasificación basada en la composición de los grupos y personas en tanto sean varones o mujeres sin que la edad sea una variable de mayor relevancia [Cuadro1]. Este acercamiento nos brinda un tipo de información sobre el total de fotografías de la colección y permite tener una cartografía panorámica de los grupos y subgrupos.

\section{Cuadro 1. Cantidades de grupos por géneros}

\begin{tabular}{|c|c|c|c|}
\hline & GRUPO A & GRUPO B & GRUPO C \\
\hline & $\begin{array}{l}45 \text { Imágenes de composición mixtas, con } \\
\text { grupos de mujeres y varones. }\end{array}$ & 22 Imágenes solo de varones. & $\begin{array}{l}5 \text { Imágenes solo de } \\
\text { mujeres y niñas. }\end{array}$ \\
\hline \multirow{3}{*}{ 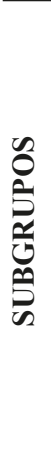 } & A.1. Retratos familiares: 30 & $\begin{array}{l}\text { B.1. Retratos de hombres } \\
\text { solos: 11, }\end{array}$ & $\begin{array}{l}\text { C.1. Retratos } \\
\text { individuales, una } \\
\text { adulta y una bebe: } \\
2,\end{array}$ \\
\hline & $\begin{array}{l}\text { A.2. Retratos grupales no familiares } \\
\text { (Iglesia, trabajo, etc.): } 10 \text {, }\end{array}$ & $\begin{array}{l}\text { B.2. Retratos de hombres en } \\
\text { grupos de } 3 \text { integrantes: } 2 \text {, }\end{array}$ & $\begin{array}{l}\text { C.2. Retratos } \\
\text { de dos y cinco } \\
\text { (mujeres y niñas): } \\
3 .\end{array}$ \\
\hline & $\begin{array}{l}\text { A.3. Actos, inauguraciones. La cámara } \\
\text { está escondida y sucede otra cosa mientras } \\
\text { se obtura. Podrían llamarse testimoniales o } \\
\text { periodísticas: } 5 \text {. }\end{array}$ & $\begin{array}{l}\text { B.3. Imágenes de grupos } \\
\text { grandes: } 9 \text {. }\end{array}$ & \\
\hline
\end{tabular}

${ }_{9}$ Con respecto a la incorporación de la norma la autora aclara que ... una norma no es lo mismo que una regla, y tampoco es lo mismo que una ley. Una norma opera dentro de las prácticas sociales como el estándar implícito de la normalización. Aunque una norma pueda separarse analiticamente de las prácticas de las que está impregnada, también puede que demuestre ser recalcitrante a cualquier esfuerzo para descontextualizar su operación. (2010:69)

${ }^{10}$ Los aparatos reguladores de la heterosexualidad están ligados al proceso de normalización y funcionan como condición de inteligibilidad cultural. Su desviación se sanciona como un ejemplo aberrante que los poderes reguladores (médico, psiquiátrico y legal) pueden explotar con el fin de reforzar sus límites. En este sentido, para la Butler de Deshacer el género (2010) la empresa fundamental es definir los parámetros de la norma y cuáles son las desviaciones que interrumpen el proceso regulador. La definición de los poderes médicos y psiquiátricos como reguladores, es retomada por la autora de su principal antecedente Michel Foucault.

${ }^{11}$ Las fotografías no reproducidas se identificarán por su número de inventario. 


\section{Grupo A: mujeres y varones.}

Este es el conjunto más numeroso. En estas imágenes aparecen grupos mayores de mujeres, hombres, niños y niñas vinculados familiarmente o no. Aquí están los tradicionales retratos familiares escenificados y por encargo, donde se resalta la estructura de la familia heteronormativa en la mayoría de los casos con abuelas, abuelos, hermanas, hermanos de los padres y madres, etc. En algunas situaciones el grupo primario aparece representado también en fotos (foto con fotos) como en la boda [Figura 1] donde la mujer tiene puesto un vestido de novia con el correspondiente tocado y en la mesa del centro hay dos fotografías de distintos tamaños encuadradas y dos más en el piso. ${ }^{12}$

Figura 1. Inv. 214

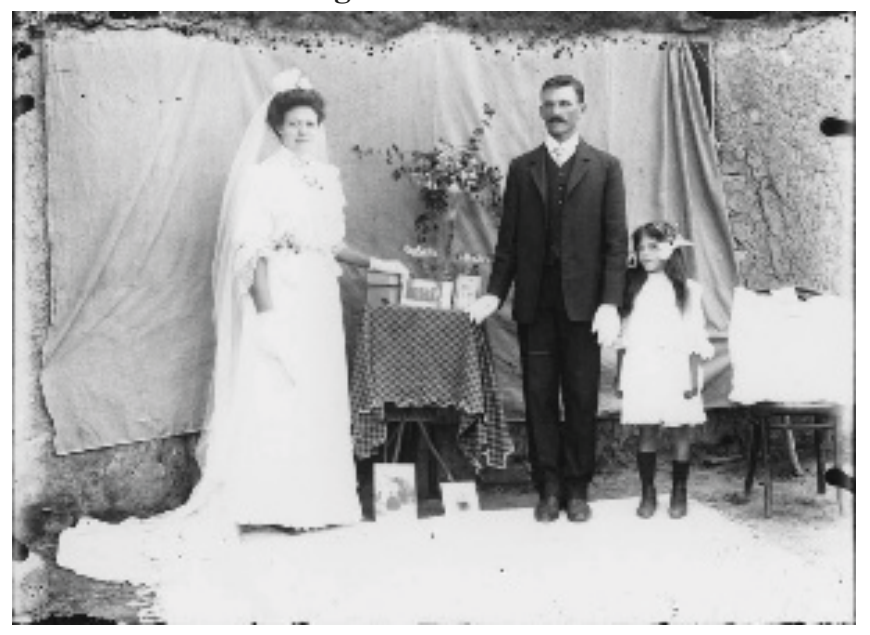

Las funciones de los retratos familiares han sido ampliamente estudiadas y son variadas. Resaltan la cohesión interna del grupo y su crecimiento como manifestación de salud y normalidad (Hirsch, 1999) además sirven para describirlo a la vez que lo inscriben en una identidad social determinada. También la organización familiar misma, adopta diversas particularidades según el modo de producción de la subsistencia para cada sociedad, es así que las familias rurales han sido extensas debido a que el trabajo se realiza con el concurso de sus integrantes (Gamba, 2009: 135). En todas las fotografías hay una centralidad del plano en los varones, en especial una fuerte relevancia de la función del padre de familia. La investigación sobre la composición de la familia heterosexual monógama ha servido de clave principal para analizar los roles y la división del trabajo desde la modernidad. La heterosexualidad obligatoria, la concreción de la

\footnotetext{
${ }^{12}$ Hay dos textos centrales, en los que se trabajará la escenificación del retrato familiar. Ellos son el de Andrea Torricela, Género, prácticas de re-presentación familiares/personales y fotografías. Usos y sentidos de la propia imagen y su devenir doméstico. Argentina, 1930 a fines de 1960. Si bien analiza un periodo posterior al fotografiado por Simoni, desarrolla las bases metodológicas del tratamiento en especial referencia a la perspectiva que nos interesa. El otro es la recopilación producto de una exhibición y conferencia en Hanover en 1996, The Familial Gaze, deMarianne Hirsch (1999).
} 
norma y sus consecuencias se construyen en las imágenes como el principio estabilizador y regulador. La matriz heterosexual refiere a una supuesta complementariedad de los cuerpos y se refuerza otorgando realidad a la masculinidad y femineidad ideal. La regulación biopolítica de las funciones y movimientos se cimenta en estas citas y organizaciones del espacio y el trabajo, incluyendo las posibilidades futuras y los próximos roles, para el caso de niñas y niños. El discurso de la heteronormatividad tiene componentes que lo conforman como realidad normativa y que pueden individualizarse para su análisis. Entre ellos podemos mencionar la pasividad sexual de las mujeres, que asegura la limpieza de la sangre y el no derroche de la herencia en descendencia no "legítima" traducida en la pureza del vestido blanco de la novia [Figura 1]. Otro relato fundamental de la heteronormatividad es el mito del amor romántico que refuerza dicha pasividad y sobrecarga a los varones con la ritualidad del cortejo. Quien cierra la trilogía es la invención del "instinto materno" funcionando como regla intrínseca de división de los espacios de circulación y de distribución del tiempo y las tareas. En las imágenes que analizamos se configura esta norma como es el caso de este particular retrato familiar [Figura 2].

Figura 2. Inv. 217

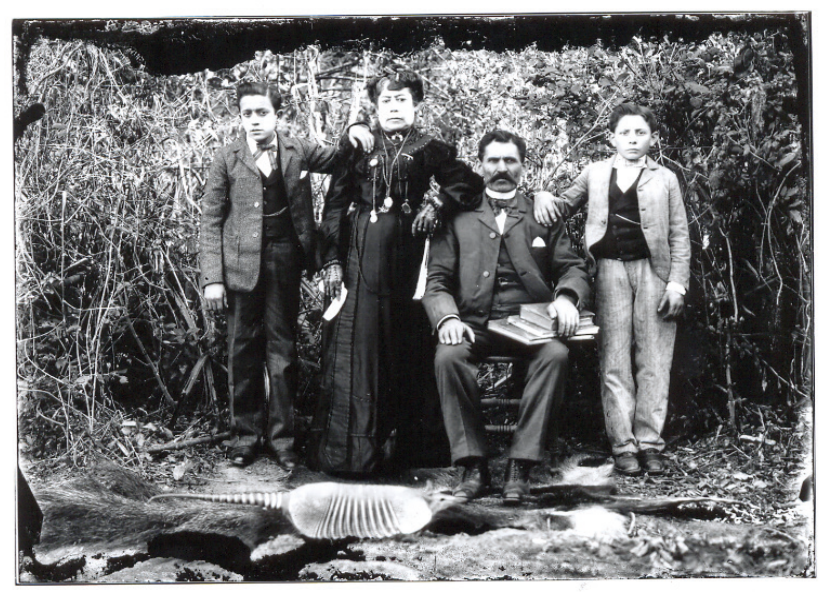

\section{División de los subgrupos}

A. 1. Retratos familiares: 30 imágenes.

A. 2. Retratos grupales no familiares, iglesia, trabajo, etc.: 10 imágenes.

A. 3. Actos, inauguraciones, donde está ocurriendo otra cosa mientras la cámara se obtura. Podrían ser consideradas predominantemente testimoniales o periodísticas: 5 imágenes.

\section{Grupo B: solamente varones}

Compuesto por 13 imágenes de retratos escenificados, de edades variadas. Para la organización se dividió en: 
B1: 11 imágenes de hombres solos,

B2: 2 imágenes en grupos de tres,

B3: 9 imágenes de grupos grandes.

\section{Subgrupo B1}

El subgrupo B1 está compuesto por retratos de varones solos, con y sin caballos. ${ }^{13}$ Hay en total seis imágenes diferentes donde aparecen hombres (cinco de ellas son composiciones con telas haciendo de fondo ${ }^{14}$ ). De todas las imágenes en una sola el protagonista mira a la cámara ${ }^{15}$ y posee una medalla colgada de una larga cadena sobre el chaleco oscuro. Un cura al aire libre es retratado [Figura 3] con una biblia en la mano, cerca de lo que parece ser una parra y en el fondo se entrevé un alambre tejido.

Figura 3. Inv. 201

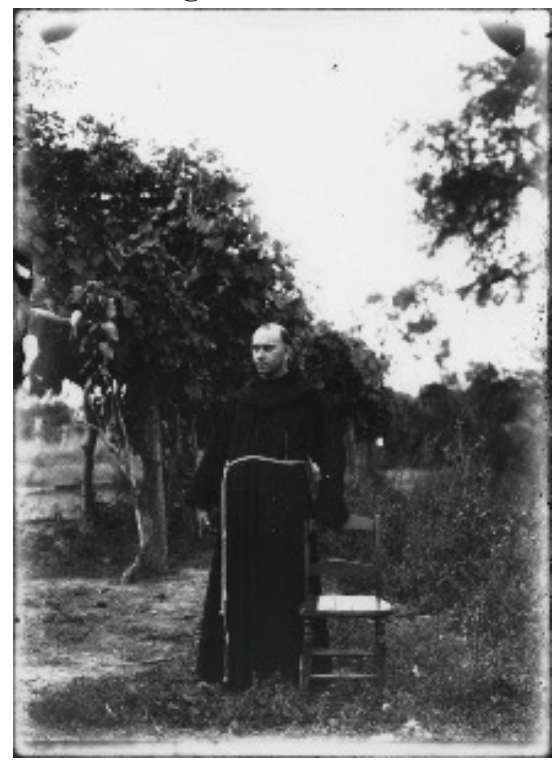

Un hombre de mediana edad es retratado tocando una silla con su mano izquierda [Figura 4] en la que hay un arma corta de fuego. El protagonista no mira al objetivo y tiene el mentón levemente erguido.

Los retratos son instancias de producción de significados donde las clases sociales reivindican su presencia en la representación y obtención de cosas (y bienes)

\footnotetext{
${ }^{13}$ Se destacan también en inv. 165 un hombre a caballo con calchas y ropas lujosas mirando al objetivo e inv. 241 hombre mayor con habano y sobre un caballo, no mira al objetivo.

14 Práctica extendida hasta que se constituye la foto de estudio.

${ }^{15}$ Inv. 194
} 
que puedan poseerse ${ }^{16}$. Ha sido el ascenso de la clase media y media baja lo que produjo en el siglo XIX la demanda de grandes cantidades de estas reproducciones (Hirsch, 1999; Didi-Huberman, 2014; Tagg, 2005). Para la construcción de la masculinidad en las imágenes se ha recurrido a retratos de hombres en solitario, que abundan, a diferencia de la proporción de mujeres retratadas individualmente. Los retratos individuales son signos de poder y rinden culto a la personalidad. Los varones de las imágenes performan llenando la escena, es así que su proyección simbólica justifica el retrato individual.

Las estampas analizadas cumplimentan los rasgos de lo que en estudios de masculinidades se denomina el ideal del hombre maduro donde no están presentes trazas de feminidad (esto incluye no parecer una mujer en ningún aspecto ni ser pasible de resultar deseado por un hombre); exigencia de superioridad (ser admirable); valentía e independencia (no mostrar emociones ni signos de debilidad) por último fuerza y agresión. (Badinter, 1993). Las marcaciones del lenguaje corporal que hallamos coinciden en acentuar los rasgos que distinguirían a un varón maduro y la confección de estas imágenes refuerzan esa norma.

Figura 4. Inv. 244

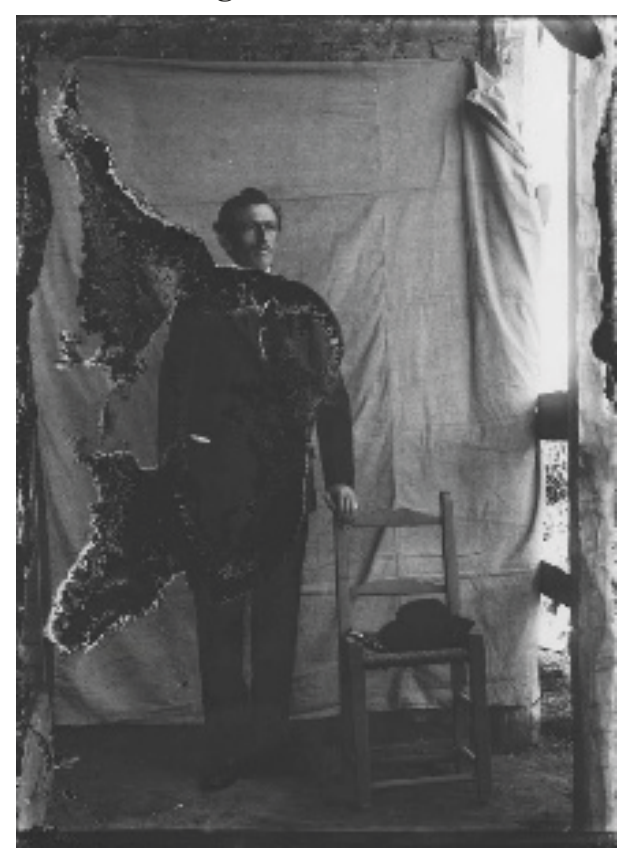

${ }^{16}$ La historia de la fotografia es (...) una historia de necesidades alternativamente fabricadas y satisfechas por un flujo ilimitado de mercancias; un modelo de crecimiento capitalista en el siglo XIX. En ningún otro aspecto esto es tan evidente como en el ascenso del retrato fotográfico que corresponde a una etapa concreta de la evolución social: el ascenso de las clases medias y medias bajas hacia una mayor importancia social, económica y política (Tagg, 2005: 54). 


\section{Subgrupo B2}

El subgrupo B2 está integrado por dos copias con tres hombres cada una, sentados y sobrecaballos. En este retrato masculino [Figura 5] uno de ellos tiene un cigarrillo casi consumido en la boca y al observar detenidamente comprobamos que ninguno mira directamente a la cámara. Sí se observa un cruce de miradas entre los tres. El protagonista central ubicado en el medio, posee la mano izquierda enguantada, podría faltarle un dedo o la mano misma. Los tres lucen vestidos con ropas lujosas, broches en las solapas y aspecto arreglado, por sobre la media. Se destacan los zapatos nuevos del protagonista de la izquierda. La escena está envuelta en una excesiva dramatización, casi paródica de seriedad que coincide con una búsqueda de solemnizar los espacios cotidianos (Reyero y Sudar Klappenbach, 2010). Es también una muestra ostentosa de la moda masculina de la época que al mismo tiempo hace emerger a la norma genérica de virilidad ligada al ascenso social.

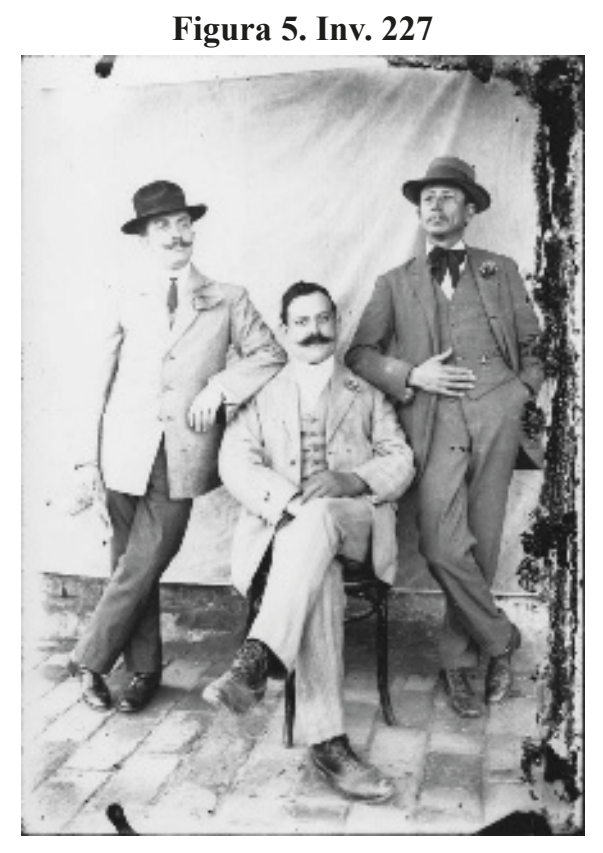

En la siguiente imagen [Figura 6] se retratan tres varones jóvenes montando cuidados caballos. El personaje del medio tiene un clavel claro en el ojal izquierdo del saco. Todos llevan ropa arreglada además de sombreros. Visten saco y moños bancos en el cuello. Miran directamente al objetivo frunciendo el entrecejo con gesto adusto. El protagonista del medio vuelve a aparecer en otra imagen solo y con otro caballo, a su lado y no sobre el animal. ${ }^{17}$

\footnotetext{
${ }^{17}$ Inv. 165
} 
Figura 6. Inv. 196

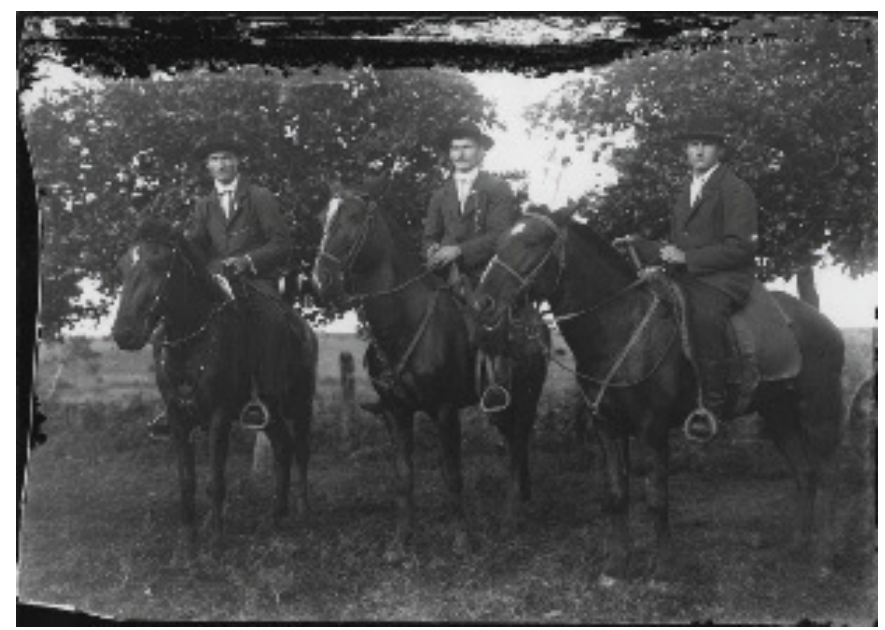

\section{Subgrupo B3}

Este subgrupo está integrado por nueve imágenes de varones en agrupamientos de mucha cantidad. Son en su mayoría escenas de trabajo (seis de ellas sobre un total de nueve). Se destacan las escenas de labradores en el campo sobre máquinas, la inauguración de un ferrocarril, hombres sobre un puente de madera, dos imágenes deportivas (futbol) y una fotografía dentro de un depósito de algodón ${ }^{18}$.

Didi-Huberman (2014) menciona cómo en el siglo XIX las imágenes de multitudes suscitan un miedo especial que el autor conecta con las consecuencias anímicas de la Revolución Francesa y la perspectiva jurídica sobre las asociaciones de malhechores y la multitud criminal. La regla de los retratos grupales es que esté presente algún orden de jerarquías para anular el signo de una atemorizante jauría informe. El grupo se piensa en el peor de los casos como un rebaño y en el mejor como una tropa (:62). Bajo esa norma Simoni elabora las imágenes de estos grupos. ${ }^{19}$ En el presente subgrupo destacamos la fotografía de un acto eleccionario [Figura 7] ya que propicia la indagación histórica sobre quien la encargó y el momento en que ocurrió.

\section{Conclusiones preliminares del grupo B}

Las fotos donde aparecen varones solos o en grupos casi triplican la cantidad de imágenes con respecto al grupo C (imágenes solo de mujeres y niñas) y también

\footnotetext{
${ }^{18}$ Invs. 221; 222; 213; 186 y 200; y 188 respectivamente.

${ }^{19}$ Esto no responde a un mandato explicitado. Consideramos siguiendo a Didi-Huberman que...Lo ideal es subsumir al grupo en la autoridad de lo Mismo o de lo Uno: mismidad de cada quien para formar un solo todo social, unidad de la regla que reúne sociablemente a cada cual con todos. (...) la paranoia medieval sobre las brujas o los untori (untadores) de la peste negra es reemplazada ahora por la paranoia ante el crimen oculto en la multitud y anónimamente producido por ella (...) se inventará un arte del retrato de grupo destinado a escrutar las multitudes, señalar en ellas las facies dudosas y poner de manifiesto los rostros de los reincidentes. (2014: 63).
} 
en la variedad de maneras de presentación, en solitario, en grupos de tres, con caballos, objetos, etc. En los retratos siempre hay una mirada altiva o desafiante de los protagonistas frente a la cámara (por ejemplo con el mentón levemente hacia arriba) aunque no siempre miran al objetivo en ocasiones tienen una mirada al vacío. ${ }^{20}$ Hay cuidado en las ropas, postura erguida y sin expresión en el rostro.

En nuestro corpus no hay fotografías en que se escenifiquen retratos de hombres solamente con niños o niñas. Hay menores en los grupos grandes entre la multitud y en los retratos familiares, pero no en los retratos masculinos. También hay niños y niñas sin adultos. ${ }^{21}$ Es necesario detenernos aquí para una descripción más detallada. Exceptuando el retrato escolar ${ }^{22}$ [Figura 15] que también podría describirse como una escena de trabajo, no hallamos fotos en que estén varones adultos sin mujeres, compartiendo la escena con niños o niñas. En tanto hay fotos de mujeres y niñas, con niñas y niños. Los ejemplos son el retrato de una madre e hijo ${ }^{23}$, una madre e hija ${ }^{24}$, y un retrato infantil ${ }^{25}$ de entre las reproducidas en este artículo. Entre las que no reproducimos, pero integran la colección se agrega inv. 219 donde hay una niña de aproximadamente siete años con un bebe sin ropas. Esto contabiliza en la totalidad del corpus, una fotografía de un varón adulto con niños y niñas y cuatro fotografías de una mujery una niña, con niños y niñas.

Figura 7. Inv. 176

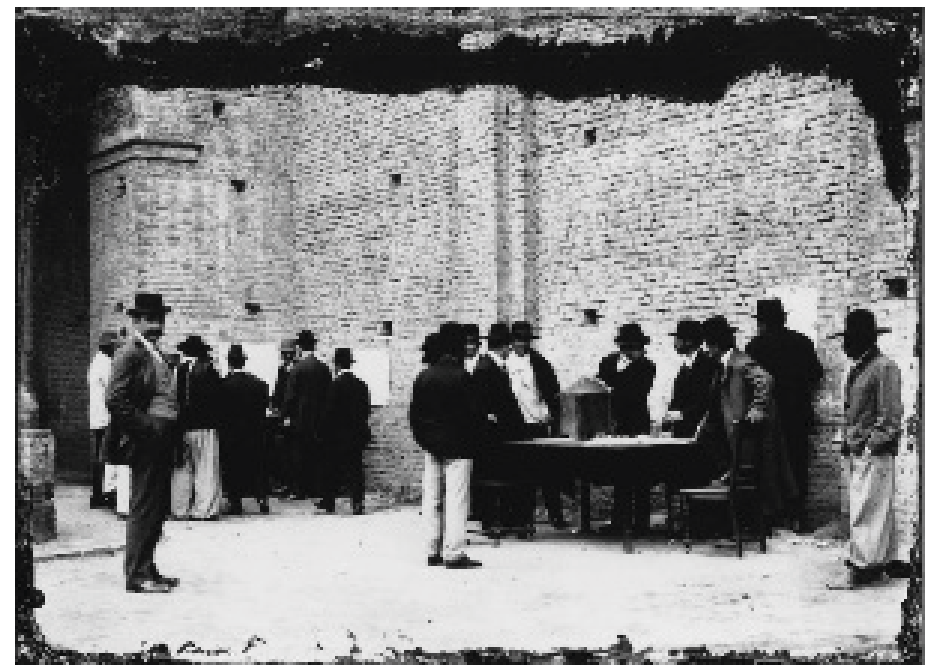

\footnotetext{
${ }^{20}$ Es la solemnidad de la mirada al porvenir o a la posteridad.

${ }^{21}$ Los dos retratos infantiles (invs. 198 y 236) entre las que reproducimos. Además, invs. 251, 181 y 212 , entre las que no reproducimos aquí.

22 Inv. 242

${ }^{23}$ Inv. 175

${ }^{24}$ Inv. 177

25 Inv. 198
} 
Los varones son retratados trabajando o en actividades públicas casi exclusivamente, salvo en las escenas familiares. En varias imágenes hay hombres cerca del ferrocarril ${ }^{26}$. Su llegada está en consonancia con la nueva infraestructura de transporte que requiere el desarrollo productivo de la región. El tren es el símbolo del "empuje civilizador" y está vinculando fuertemente la idea moderna de progreso con el ejercicio de la masculinidad. Los varones son retratados conectados a la civilización (votando o con ropas citadinas como en Figura 7) y la domesticación de lo salvaje (montando animales, como en Figura 6). ${ }^{27}$

\section{Grupo C: mujeres y niñas}

Compuesto por cinco imágenes de mujeres, bebes y niñas. Se destaca un grupo de mujeres en el jardín [Figura 8] una foto de cinco jóvenes, dos sentadas en primer plano y detrás de ellas tres de pie de rasgos que hacen suponer que son hermanas o familiares. La posición de sus cuerpos es rígida y solemne, es probable que las dos sentadas sean mayores que el resto. Las protagonistas miran a la cámara vistiendo ropas lujosas y arregladas, zapatos con medias y accesorios en las manos de acuerdo a la moda del momento. La escena es en un patio con una pared de ladrillos de fondo y una enredadera que sube por ella.

Figura 8. Inv. 178

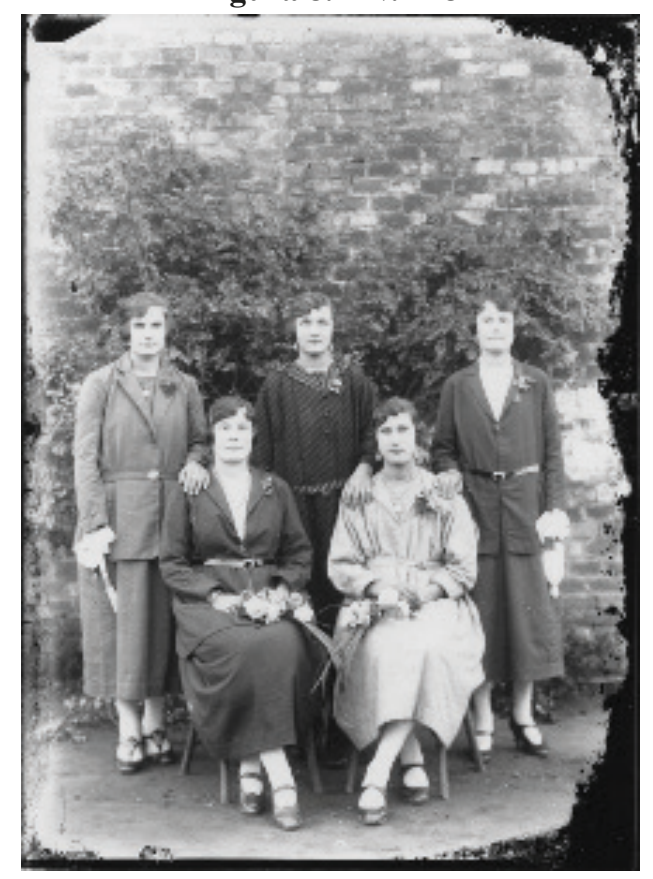

\footnotetext{
${ }^{26}$ Inv. 249

${ }^{27}$ Hay varones adultos sobre caballos en invs. 172, 216 y 241.
} 
En el siguiente retrato infantil [Figura 9] hay una bebé que ríe, con pequeños aros de argolla en sus orejas, sentada en una silla y una niña de alrededor de siete años a su cuidado, tocándola con su mano izquierda. En el rostro de la criatura menor se ve espontaneidad, sin embargo aparece fastidio en la expresión facial de la niña que está de pie.

En el caso del otro retrato [Figura 10] aparece sentada la misma bebé de la Figura 9, pero esta vez el encuadre se acerca un poco más. Pensamos que fue posterior, por la oscuridad de la escena (hay menos luz sobre el rostro) y la niña muestra señales de haber llorado o estar llorando, así como los puños cerrados y los ojos hinchados. En ambos casos la silla y el escenario son los mismos.

Figura 9. Inv. 198

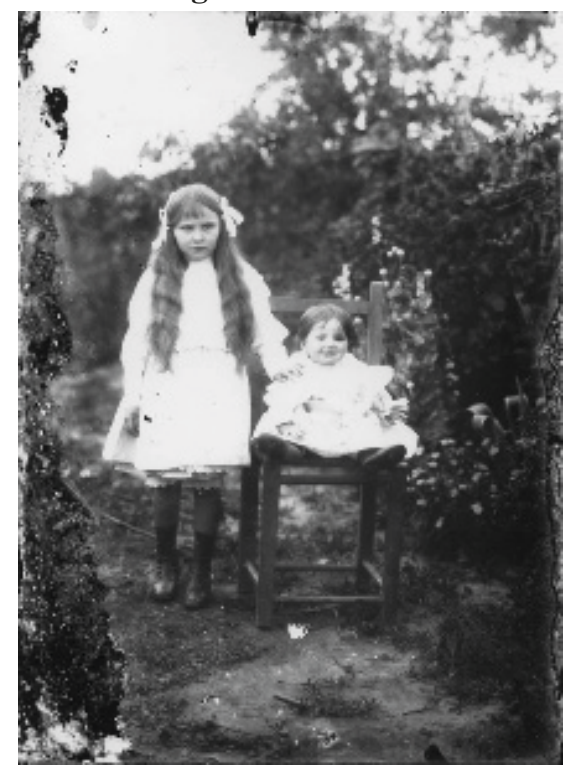

Figura 10. Inv. 236

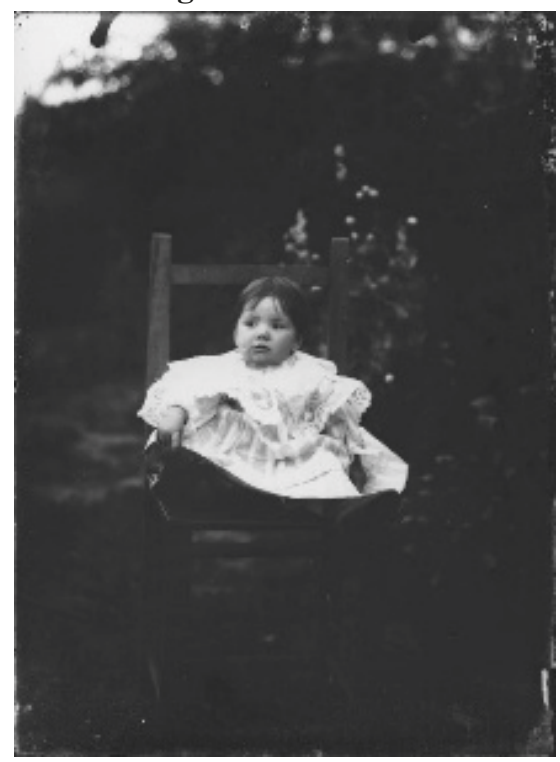

En la siguiente [Figura 11] vemos una mujer de pelo corto o recogido y una niñaa su derecha (con aros de argolla). La niña tiene un ramo de flores en sus manos. Ambas visten ropas oscuras ${ }^{28}$ ymiran directamente a la cámara.

A continuación destacamos [Figura 12] el único retrato individual de una mujer de toda la colección, sin infantes a su alrededor y en un encuadre cercano al rostro ${ }^{29}$. La protagonista tiene el cabello recogido y se muestra con ropas claras y rostro hierático en tanto no mira a la cámara sino a un punto indefinido a su izquierda.

\footnotetext{
${ }^{28}$ Lo que nos permite inferir un duelo, aunque también puede tratarse de una expresión solemne sin más

${ }^{29}$ El plano corto aparece en pocas oportunidades, lo vemos en invs. 195, 236 y 237.
} 
Figura 11. Inv. 177

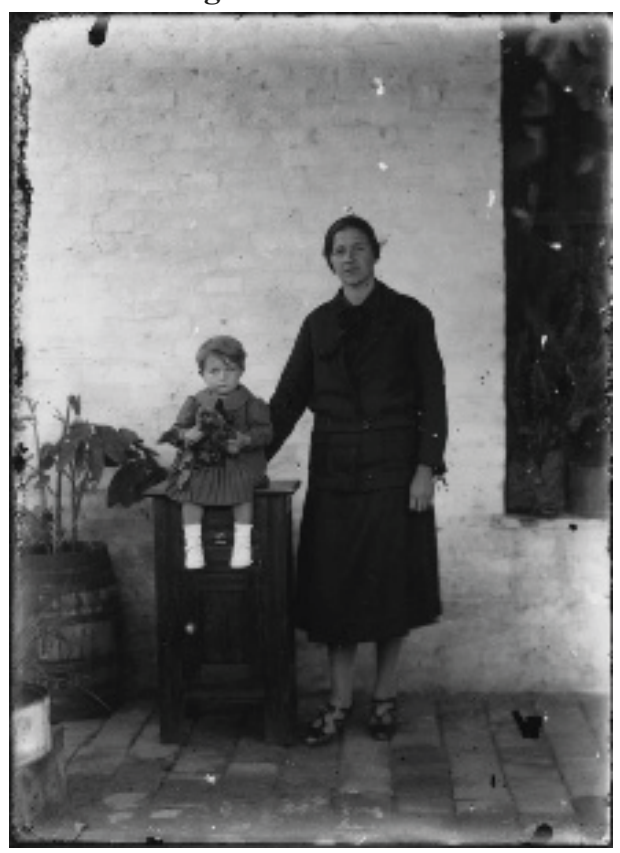

Figura 12: Inv. 237

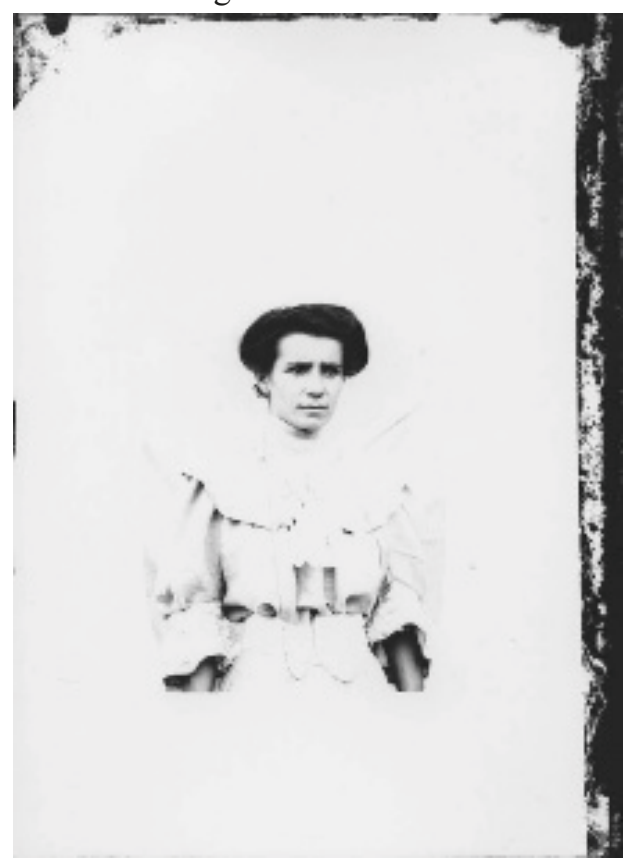

\section{Conclusiones preliminares del grupo $\mathrm{C}$}

En contraposición con la cantidad de hombres que son retratados individualmente en grupos de trabajos y actividades públicas, hay escasa representatividad de retratos de mujeres sin niños o niñas en las escenas y solamente un caso de una adulta sola frente al objetivo.

La manera en que los cuerpos de las mujeres se retratan reviste una construcción activa de la norma y el género. En su mayoría aparecen al cuidado de menores, en retratos familiares y muy pocas veces solas. El retrato individual en las mujeres contraviene la función de indiferenciar las agrupándolas, así explicamos la desproporción numérica entre retratos individuales de varones y mujeres, a favor de estos: once varones retratados en solitario, sobre dos mujeres. Las imágenes no se toman en referencia a un cuerpo puro, que no existe fuera de los discursos que instauran la norma. Los aparatos reguladores de heterosexualidad ${ }^{30}$ (Butler, 2008: 33) confieren biopolíticamente hablando el estatus a los cuerpos. Y podríamos decir que los retratos funcionan como dispositivos normativos que regulan la corporalidad de las mujeres y norman sus modos y espacios de circulación. La referencia al decoro (prematrimonial), la pasividad en los trabajos y las tareas de cuidado de ancianas, ancianos y menores surgen como las pautas que solidifican la heteronormatividad y la proyectan como un estado de normalidad sexuada, para que esta información llegue a las personas destinatarias de las fotografías en sus lugares de origen.

\footnotetext{
${ }^{30}$ Que como mencionamos son llamados también por la autora regímenes sexuales reguladores (:38).
} 


\section{Sonrisas, escuela, etc.}

Algunas de las mujeres y niñas retratadas en la colección, sonríen y miran a la cámara, son los casos de invs. 202, 211 y 247. Menos son los casos donde hombres sonríen, encontramos uno en el retrato familiar del inv. 252 [Figura 13] donde hay una mueca tímida en el adulto que podría leerse como una sonrisa. Un niño también sonríe en inv. 245 y es una niña quien sonríe en inv. 211. Un cura ríe abiertamente y mira a la lente en un escenario con muchas personas donde hay niñas y niños que han tomado la comunión $^{31}$. Las sonrisas pueden obedecer a un pedido explícito por parte del fotógrafo como a un contrato tácito que se activa frente a la cámara y cuando son naturales demuestran lo inabarcable de la representación fotográfica (Giordano y Reyero, 2010: 81) y subvierten la captura y sujeción por parte de la maquina (Sontag, 2006).

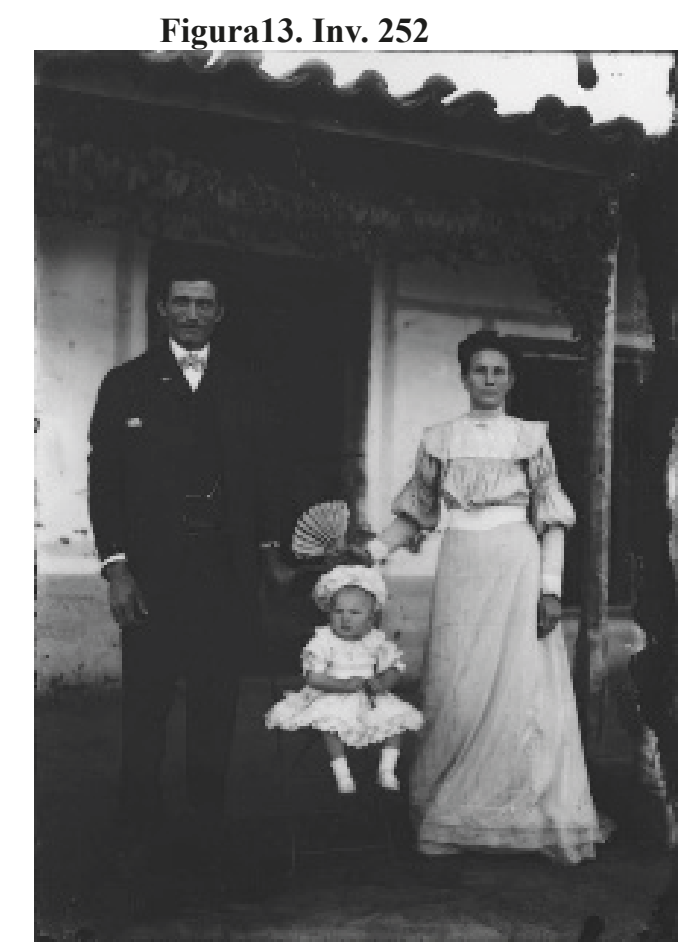

De este grupo de protagonistas sonriendo destacamos la belleza de inv. 175 [Figura 14]. Niñas y niños son fotografiables por excelencia y resguardar la infancia del paso del tiempo ha sido una de los mandatos principales de la fotografía, así como el recuerdo de quienes ya no están. La progenie y la exhibición de la infancia era leído como un momento feliz de la familia y reforzaba la idea del progreso material como manifestación de ascenso social (Torricela, 2011; Didi-Huberman, 2014).

\footnotetext{
${ }^{31}$ Inv. 183
} 
Figura 14. Inv. 175

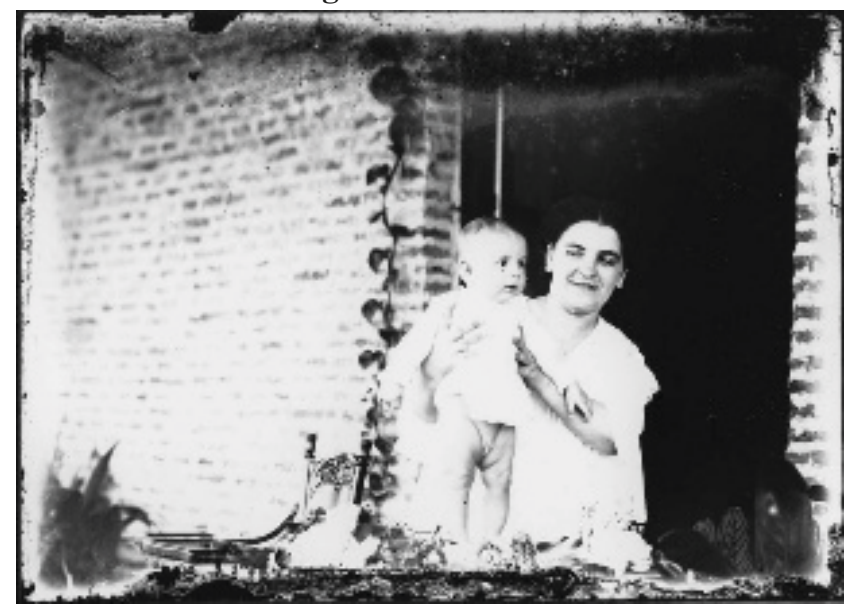

Por otra parte, hay imágenes tomadas en grupos en los espacios de socialización secundaria, escuela, clubes, comedor ${ }^{32}$, iglesia y hasta una banda musical en una reunión familiar ${ }^{33}$. Sobresalen en cantidad las tomas de niñas y niños con motivo de la primera comunión o algún sacramento de la iglesia católica que tienen como centro de la imagen al eclesiástico.

De entre todas estas seleccionamos un retrato escolar [Figura 15] por tratarse de la única fotografía tomada a un grupo compuesto por alumnos y alumnas de distintas edades a cargo de un solemne maestro, vestido con corbata. El grupo cuidadosamente ordenado por alturas y parado sobre gradas, está integrado por veintitrés estudiantes y de entre quienes componen la fila inferior solo un par poseen zapatos.

Figura 15. Inv. 242

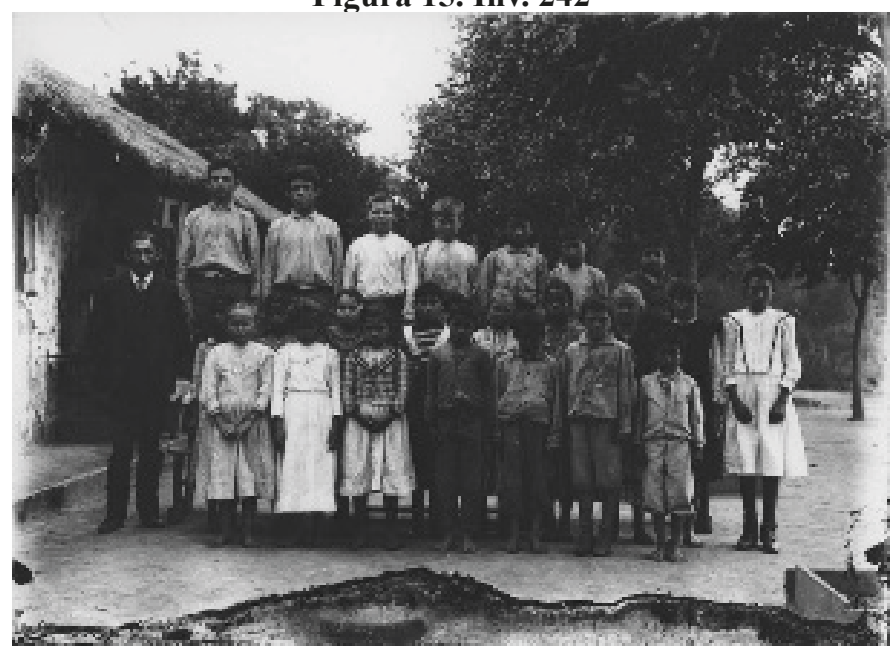

\footnotetext{
32 Inv. 163

33 Inv. 243
} 


\section{La norma hace al género}

El acercamiento y estudio de la colección permitió indagar en los tópicos reiterados a la hora de elegir los escenarios de las imágenes fotográficas de la primera parte del siglo XX en las primeras colonias del Chaco. La posibilidad de establecer categorías nomencladoras es apenas una división arbitraria para comenzar un trabajo de indagación que prosigue. Sirvió para acercarnos a los objetos y dimensionar las temáticas que se escenifican. El material trabajado posee una relevancia histórica fundamental que posibilita percibir los imaginarios que componen las escenas. El funcionamiento de la fotografía como testigo en algunos casos de hechos, mediatiza una reapropiación del pasado y un dialogo abierto con las memorias en construcción. Teniendo presente que es una tecnología plena y dadora de sentidos con valor político social y cultural, a la vez que una práctica que construye y consolida discursos e ideología.

Se producen en el dispositivo fotográfico sujetos generizados insertos en un régimen de sentido en continuo devenir. Las imágenes han funcionado como construcciones discursivas que hacen que en su seno nazcan los sujetos protagonistas que reiteran la norma de lo masculino y lo femenino como verdades naturales. Los géneros diferenciados y la heteronormatividad humanizan a los individuos, que sufre sanciones cuando no se representan bien, dado que el régimen de poder acompaña al régimen de sentidos. Como no hay una esencia que el género exprese o exteriorice ni un ideal objetivo al que aspire, puesto que no es un hecho, los distintos actos producen el concepto de género y sin ellos no habría generización; pese a ser una construcción que disimula su génesis irrastreable.

Las imágenes de la colección cimentan los géneros como identidades débilmente formadas en el tiempo e instauradas en un espacio mediante la reiteración de actos. El efecto se crea por medio de la estilización del cuerpo y por consiguiente debe entenderse como la manera mundana en que los diferentes tipos de movimientos y estilos crean la ilusión de un yo constante. No debe confundirse mundano como sinónimo de urbano ya que como explicamos antes, protagonistas y escenarios pertenecen a contextos no urbanos, aunque influidos por los ideales de la burguesía europea del siglo XIX. Los atributos son entonces performativos y no expresivos y esta distinción entre expresión y performatividad es crucial. La regulación se construye con actos y atributos, con marcaciones corporal, posturas y miradas y con roles sociales.

Para concluir con fidelidad a la metodología feminista hemos intentado abordar los objetos de estudio desde un lugar donde nos homologamos en el plano con estas mujeres y niñas retratadas en sus citas de la norma. Interpretarlas y completar su genealogía nos ayuda a comprendernos en el presente y contestar a la pregunta sobre de quienes son los sentidos del pasado. 


\section{Referencias bibliográficas}

Badinter, E. (1993). XY La identidad masculina. Norma, Santa Fé de Bogotá.

Batchen, G. (2004). Arder en deseos. La concepción de la fotografía. Gustavo Gili, Barcelona.

Beck, H. (2001). "Inmigrantes europeos en el Chaco. Transición del pluralismo al crisol”. En: Cuadernos de Geohistoria Regional, №39, Resistencia, IIGHI, CONICET.

Berger, J. (1975). Modos de ver. Gustavo Gili, Barcelona.

Bolsi, A. S.C.; Osuna, L. J. y Meichtry, N. C. (1981). "Guía para ejercicios y trabajos prácticos en Geografía de la Población". En: Cuadernos Docentes, $\mathrm{N}^{\circ} 1$, Instituto de Investigaciones Geohistóricas, CONICET FUNDANOR, Facultad de Humanidades, Universidad Nacional del Nordeste, Resistencia, Corrientes.

Butler, J. (2008). Cuerpos que importan. Sobre los límites materiales y discursivos del sexo. Paidós, Buenos Aires.

Butler, J. (2010). Deshacer el género. Paidós, Madrid.

Butler, J. (2007). El género en disputa. Paidós, Barcelona.

Cortés-Rocca, P. (2011). El tiempo de la máquina. Retratos, paisajes y otras imágenes de la nación. Colihue, Buenos Aires.

Didi-Huberman, G. (2014). Pueblos expuestos, pueblos figurantes. Manantial, Buenos Aires.

Foucault, M. (2008). Historia de la sexualidad, 1. La voluntad de saber. Siglo XXI, Buenos Aires.

Foucault, M. (1998). Las palabras y las cosas. Siglo XXI, Madrid.

Friedan, B. (1965). La mistica de la feminidad. Sagitario, Barcelona.

Gamba, S. B. (Coord.) 2009. Diccionario de estudios de género y feminismos. Biblos, Buenos Aires.

Giordano, M. (2008). Discurso e imagen sobre el indigena chaqueño. Ediciones Al Margen, La Plata.

Giordano, M. y Reyero, A. (2010). "La representación fotográfica de la sonrisa en las imágenes etnográficas chaqueñas de Guido Boggiani y Grete Stern”. En: Argos 27 (53).

Giordano, M. y Sudar Klappenbach, L. (2012). Fotografía chaqueña. Puesta en valor $y$ análisis de las colecciones Simoni, Bosquetti y Raota. Consejo Federal de Inversiones.

González-Stephan, B. "Cuerpos in/a-propiados: carte-de-visite y las nuevas ciudadanías en la pardocracia venezolana postindependentista". En: Memoria y Sociedad, Bogotá, N 17 Enero/Julio 2013, P-p 14-32.

Harding, S. (Ed.) 1987. Is There a Feminist Method? Feminism and Methodology. Indiana University Press, Indianapolis. (Traducción de Gloria Elene Bernal).

Hirsch, M. (Ed. by). 1999. The familial Gaze. Darmouth College, University Press of New England, Hanover and London.

Iturriza, M. y Pelazas, M. (2001). Imágenes de una ausencia. La presencia de la mujer en la fotografía de prensa argentina de 1920 a 1930. Prometeo, Buenos Aires.

Puleo, A. H. 2000. Filosofia, género y pensamiento crítico. Universidad de Valladolid, Valladolid. 
Reyero, A. y Sudar Klappenbach, L. (2010). "Memorias de la inmigración. Historias de vida de los inmigrantes europeos en el Chaco a través de sus fotografías". En: Quinto Sol, $\mathrm{N}^{\circ} 14,2010$, pp. 73-99.

Richard, N. (2009). "La crítica feminista como modelo de crítica cultural". En: Debate Feminista, Vol. 40, octubre. P-p 75-85.

Santa Cruz, M. I.; Bach, A. M.; Femenías, M. L.; Gianella, A. y Roulet, M. (1994). Mujeres y filosofía I. Teoría filosófica de género. Centro Editor de América Latina, Buenos Aires.

Sontag S. (2006). Sobre la fotografía. Alfaguara, Buenos Aires.

Tagg, J. (2005). El peso de la representación. Gustavo Gili, Barcelona.

Torricella, A. (2011). Género, prácticas de re-presentación familiares/personales y fotografías. Usos y sentidos de la propia imagen y su devenir doméstico. Argentina 1930 a fines de 1960. Tesis de doctorado, Universidad Nacional de Quilmes.

Torricella, A. (2009). "La relación lenguaje-cuerpo-performatividad en la obra de Judith Butler: una cartografía”. En: Debate Feminista, Vol. 40, octubre. Pp. 229-239. 
